\title{
Numerical Taxonomy Study of Vibrio and Spirillum spp.
}

\author{
J. F. CARNEY, L. WAN, T. E. LOVELACE, ${ }^{1}$ aND R. R. COLWELL \\ Department of Microbiology, University of Maryland, College Park, Maryland 20742
}

\begin{abstract}
One hundred and seven strains of Vibrio and Spirillum were examined for 175 morphological, physiological, biochemical, and nutritional characteristics. The results were analyzed by the method of numerical taxonomy. The deoxyribonucleic acid base composition of the Spirillum strains was also determined. Marked phenetic differences were found between Vibrio and Spirillum, with species of the genus Vibrio demonstrating more versatile biochemical capabilities. The numerical taxonomy and molecular genetic data are in agreement with the recently suggested assignment of selected Spirillum strains to the genera Oceanospirillum and Aquaspirillum.
\end{abstract}

Interest in the classification of the genus Vibrio has focused on the pathogenic species, with attention directed toward the role of Vibrio cholerae as an infectious agent. Other members of the genus have been less completely studied. More recently, Vibrio parahaemolyticus, a causative agent of gastroenteritis in the United States $(5,9)$ and other countries $(1,2)$, has been the subject of intensive research $(3,13,22)$. Although Vibrio alginolyticus infections in man have been recorded (24), the pathogenic properties of this and other Vibrio species have not been examined fully.

Vibrio spp. are common inhabitants of seawater and marine sediments, and the relationship of members of this genus to other aquatic genera, such as Pseudomonas and Spirillum, has not been sufficiently explored. Morphological similarities between curved Vibrio and Spirillum spp. suggested to bacteriologists at the turn of the century that a strong relationship existed between these two groups. Thus, Vibrio was included as a genus in the family Spirillaceae. Recent but preliminary observations of Vibrio and Spirillum strains, included as reference strains in taxonomic studies, suggested a low level of similarity between the two genera (8). Identification of species within the genus Spirillum has been based, to a significant extent, on morphology (26-28). Extensive study of 39 Spirillum strains accomplished by $\mathrm{Hy}-$ lemon and his associates (12) led to the suggestion of a reclassification based on ecological differences, salt tolerance, and deoxyribonucleic acid (DNA) base composition. Our study was undertaken to determine the taxonomic relationships of the genera Vibrio and

\footnotetext{
'Present address: National Cancer Institute, Bethesda. Md. 20014.
}

Spirillum, as well as of selected species within these genera.

\section{MATERIALS AND METHODS}

Details concerning source and place of isolation of 107 cultures included in this study are given in Table 1. The maintenance medium consisted of yeast extract (Difco) $(1.0 \%)$, proteose peptone (Difco) $(1.0 \%)$, and a salts solution as a diluent for the marine strains. The salts solution consisted of $\mathrm{NaCl}(2.34 \%)$, MgSO $.7 \mathrm{H}_{2} \mathrm{O}(0.69 \%)$, and $\mathrm{KCl}(0.075 \%)$. A multipoint inoculation system (15) was used where appropriate. Other media were inoculated by the spot drop technique (7) or with a drop from a Pasteur pipette.

Cultures were examined for the following: colonial and cultural characteristics, Gram reaction, presence of flagella, fluorescence under ultraviolet light, and production of a water-soluble or -insoluble pigment. Presence of cytochrome oxidase, catalase, arginine dihydrolase, and ornithine, lysine, and arginine decarboxylases was observed, as were hydrolysis of aesculin, casein, starch, Tweens $20,40,60$, and 80 and urea, digestion of agar, and liquefaction of gelatin. Acid formation from adonitol, arabinose, cellobiose, dextrin, dulcitol, ethanol, fructose, galactose, glycerol, inositol, inulin, lactose, maltose, mannose, melezitose, melibiose, raffinose, rhamnose, salicin, sorbitol, sucrose, trehalose, and xylose were recorded, as were production of ammonia, carbonate, dihydroxyacetone, hydrogen sulfide, indole, lecithinase, levan, melanin, and phosphatase. Oxidative versus fermentative utilization of glucose was tested. Sensitivity to iodoacetate, the vibriostatic agent $0 / 129$ (pteridine), and to antibiotics (penicillin $[10 \mathrm{Ug}]$, dihydrostreptomycin [10 mg], chloromycetin [ $30 \mathrm{mg}$ ], erythromycin [15 mg], kanamycin [30 mg], aureomycin [30 mg], novobiocin [ $30 \mathrm{mg}$ ], polymyxin $\mathrm{B}$ [ $30 \mathrm{mg}$ ], terramycin [30 mg], and tetracycline [ $30 \mathrm{mg}$ ]) were tested. Reduction of nitrates and nitrites, presence of trimethylamine oxidase, the methyl red, Voges-Proskauer, and litmus milk reactions were also determined. The abilities to utilize acetate, citrate, formate, and malonate as sole carbon sources, ammonium phosphate as a sole nitrogen source, and $\beta$-alanine, DL-alanine, arginine, Casamino Acids, lysine, phenylalanine, and 
TABLE 1. Strains used

\begin{tabular}{l} 
Strain no. \\
\hline FDA 3525, 3782, 4203, 10734, 10981, 11587 \\
$11590,11883,12042,11759,3 A C 41$ \\
MD 8657-71 a+b, 8658-71 a+b, 8659-71, \\
$8700-71 \mathrm{a}+\mathrm{b}, 2882$ \\
RMD 341-A, 341-B, 341-D
\end{tabular}

Mullet 2, CP Mullet, Blue Gill

$\mathrm{A} 1 \rightarrow \mathbf{E b}$

V-6, V-12, V-14

Thompson K4, K5, S12T, S120

Landry $1,2,3,4$

N.H. 4, 12, 29, 31

EB101, WP1, A55, Hirakata, Toyonaka

BCL, BOH

8RR7, 9RR212, 10RR10

Ps207, Ox-Sawyer, A fischeri, SAK 3 ,

FC1011, Micrococcus CB234, E. coli, Spirillum FC281-a 3S2

ATCC 12753, Spirillum atlanticum

ATCC 12754, Spirillum beijerinckii ATCC 19192, Spirillum halophilum ATCC 19191, Spirillum japonicum ATCC 11336, Spirillum linum ATCC 11337, Spirillum lunatum ATCC 19193, Spirillum minitulum ATCC 19259, Spirillum anulus ATCC 7566, Spirillum tenue ATCC 14667, Spirillum delicatum ATCC 11334, Spirillum giesbergeri ATCC 12639, Spirillum itersonii subspecies itersonii

ATCC 15280, Spirillum metamorphum

ATCC 11332, Spirillum polymorphum

ATCC 15279, Spirillum putridiconchylium

A'TCC 12638 Spirillum serpens

ATCC 15278$\}$ subspecies serpens

ATCC 11335, Spirillum serpens subspecies azotum

ATCC 9786, Spirillum sinuosum

ATCC 15387, Spirillum peregrinum

ATCC 19624 a + b, Spirillum gracile

ATCC 19625, Spirillum gracile

ATCC 19626, Spirillum gracile

ATCC 11331, Spirillum itersonii

V.P.I. 104, 8230, 9072, 101

\begin{tabular}{|l|}
\hline Investigator \\
\hline M. Fishbein, F.D.A. Wash- \\
ington, D. C. \\
Maryland Department of \\
Health \\
P. Haefner, Virginia In- \\
stitute of Marine Science \\
L. Waddell, Fla.
\end{tabular}

H. Nakanishi, Japan

J. Thompson, Canada

P. Landry, Tex.

C. Bartley, N.H.

K. Tamura, Japan

J. Baross, Ore.

T. Kaneko, Canada

\section{J. D. Oliver, N. Carolina}

N. Krieg, Virginia Polytechnic Institute

N. Krieg
Crab isolates from food poisoning outbreak in Bainbridge, $\mathrm{Md}$.

Crab isolates from food poisoning outbreak in Bainbridge, Md.

Fish kill isolates, Va.

Fish kill isolates, Fla.

Isolates from pompano and permit

Phage host

Rhode River area of Chesapeake Bay, Md.

Control strains used routinely in numerical taxonomy studies in our laboratory

S.E. Atlantic Ocean, Spirillum spp.

Marine spirilli

Freshwater spirilla proline as sole sources of carbon and nitrogen were tested, as was the ability to grow at selected temperatures ranging from 4 to $37 \mathrm{C}$, in salt concentrations from 0 to $10 \%$, and at $\mathrm{pH}$ values from 4 to 10 . Methods and details of the procedures followed have been published elsewhere $(7,8,18)$.

Results from each of the above tests were scored for analysis by computer. In the coding system employed,
1 indicated positive result, 0 indicated negative result, and 3 indicated that the test was not applicable or not performed. The Jaccard coefficient, $S_{J}$, with negative matches excluded, was used (21). The strains were clustered by a single linkage technique, using the GTP-2 program. Feature frequencies were computed for the strain clusters using the GTP-3 program (8).

The guanine plus cytosine content (moles percent 
$\mathrm{G}+\mathrm{C}$ ) of purified DNA extracted from selected strains in this study was determined by previously described methods $(6,17)$.

\section{RESULTS}

One hundred and seven strains were examined for 175 coded characteristics. Characters uniformly negative included the following: growth in KCN, utilization of adonitol, dulcitol, inositol, inulin, melezitose, raffinose, and rhamnose, digestion of agar, and growth at $4 \mathrm{C}$. None of the strains produced gas from the carbohydrates tested. With the exception of a reference strain, Pseudomonas fluorescens strain OxfordSawyer, the tests for pigmentation, such as Sabouraud agar and King, Ward, and Raney agar, and the tests for fluorescence (i.e., Paton medium and Haynes medium) were negative. All strains grew at $25 \mathrm{C}$ and in the $\mathrm{pH}$ range 6 to 9 and were sensitive to $10 \mu \mathrm{g}$ of chloromycetin.

The similarity matrix obtained from the computer analysis is shown in Fig. 1. Eight clusters and nine strains which did not cluster with any of the eight groups were noted. Four clusters were identified as $V$. cholerae (group 1 ), $V$. parahaemolyticus (group 2), marine Spirillum strains (group 6), and freshwater Spirillum strains (group 7). The remaining clusters consisted of two or three strains each. Of the latter, groups 3,4 , and 5 showed some similarity to $V$. parahaemolyticus, whereas group 8 did not demonstrate significant relationships with any of the other strains studied. Characters found to be useful in differentiating the major groupings are listed in Table 2.

Intra- and intergroup similarity (S) values are given in Table 3 . A set of $V$. cholerae strain data, analyzed in an earlier published study (8), was included here solely for purposes of comparison. The $V$. cholerae cluster was homogeneous (intragroup $\% \mathrm{~S}=85$ ) and demonstrated an intergroup similarity of approximately $75 \%$ with $V$. parahaemolyticus. A low degree of similarity ( 38 to $39 \%$ ) was observed between Vibrio spp. and Spirillum spp. and the other clusters obtained in this study.

Despite varied geographical sources, the $V$. parahaemolyticus strains (cluster 2) displayed a high intragroup similarity value, $\mathrm{S}=83 \%$. A very high degree of relatedness, $S \geq 92 \%$, was noted among eight $V$. parahaemolyticus isolates (labeled FDA strains) and $V$. parahaemolyticus FC1011. Several of these FDA strains of $V$. parahaemolyticus and strains of this species obtained from the Maryland Department of Health (isolated from the same $V$. parahaemolyticus outbreak in Bainbridge, Md. in 1971 [9]) were found to be related at $\mathrm{S}>90 \%$. Eleven strains isolated from Pompano fish in mariculture were highly related to each other and, interestingly, were sucrose utilizers. The $V$. parahaemolyticus phage hosts V-6 and V-14 were included in the cluster at $\mathrm{S}=77$ and $78 \%$. These strains differed from the clustered strains and from each other mainly in antibiotic sensitivities, cultural and colonial morphology, and salt and $\mathrm{pH}$ tolerances.

The three luminescent organisms (cluster 3) demonstrated in intragroup similarity of $85 \%$ and were included in the $V$. parahaemolyticus cluster at $\mathrm{S}=80 \%$. Although similar to $V$. parahaemolyticus in cultural and colonial characteristics, these strains could be differentiated on the basis of bioluminescence, inability to utilize arginine, citrate, or formate, and requirement for added sodium chloride.

Clusters 4 and 5, consisting of two strains each, did demonstrate some degree of similarity with $V$. parahaemolyticus. The Pompano isolates (cluster 4), which can be described as polarly flagellated, gram-negative, fermentative, non-gas-producing rods, were unable to utilize citrate, dextrin, fructose, formate, glycerol, maltose, malonate, or trehalose or to hydrolyze starch or gelatin, and lacked both the lysine and ornithine decarboxylases. The difference in biochemical abilities, in conjunction with the low ( $\mathrm{S}=71 \%$ ) similarity to $V$. parahaemolyticus, precludes their identification as members of this species. The data obtained on cultural and colonial characteristics, biochemical abilities, and $\mathrm{mol} \% \mathrm{G}+\mathrm{C}$, permit a similar conclusion concerning the Thompson cultures (cluster 5), which joined the $V$. parahaemolyticus cluster at $\mathrm{S}=69 \%$.

The Spirillum strains formed two groups, clusters 6 (marine) and 7 (freshwater), which were clearly distinct from each other and from the other groups. Although a low intergroup similarity $(S=46 \%)$ was observed for these two groups, neither group, by itself, was markedly homogeneous (cluster $6, \mathrm{~S}=66 \%$; cluster $7, \mathrm{~S}=$ $64 \%$ ). Differentiation of the groups was possible on the basis of morphology and sodium chloride requirement (Table 2). Individual freshwater Spirillum strains could be distinguished by their ability to hydrolyze gelatin, utilize Casamino Acids, arginine, DL-alanine, $\beta$-alanine, lysine, and proline. There was, however, no definitive set of characteristics which served to identify this group of strains. Spirillum lunatum, originally classified as a marine strain and listed by the American Type Culture Collection as such, did not demonstrate a require- 
VoL. 25, 1975
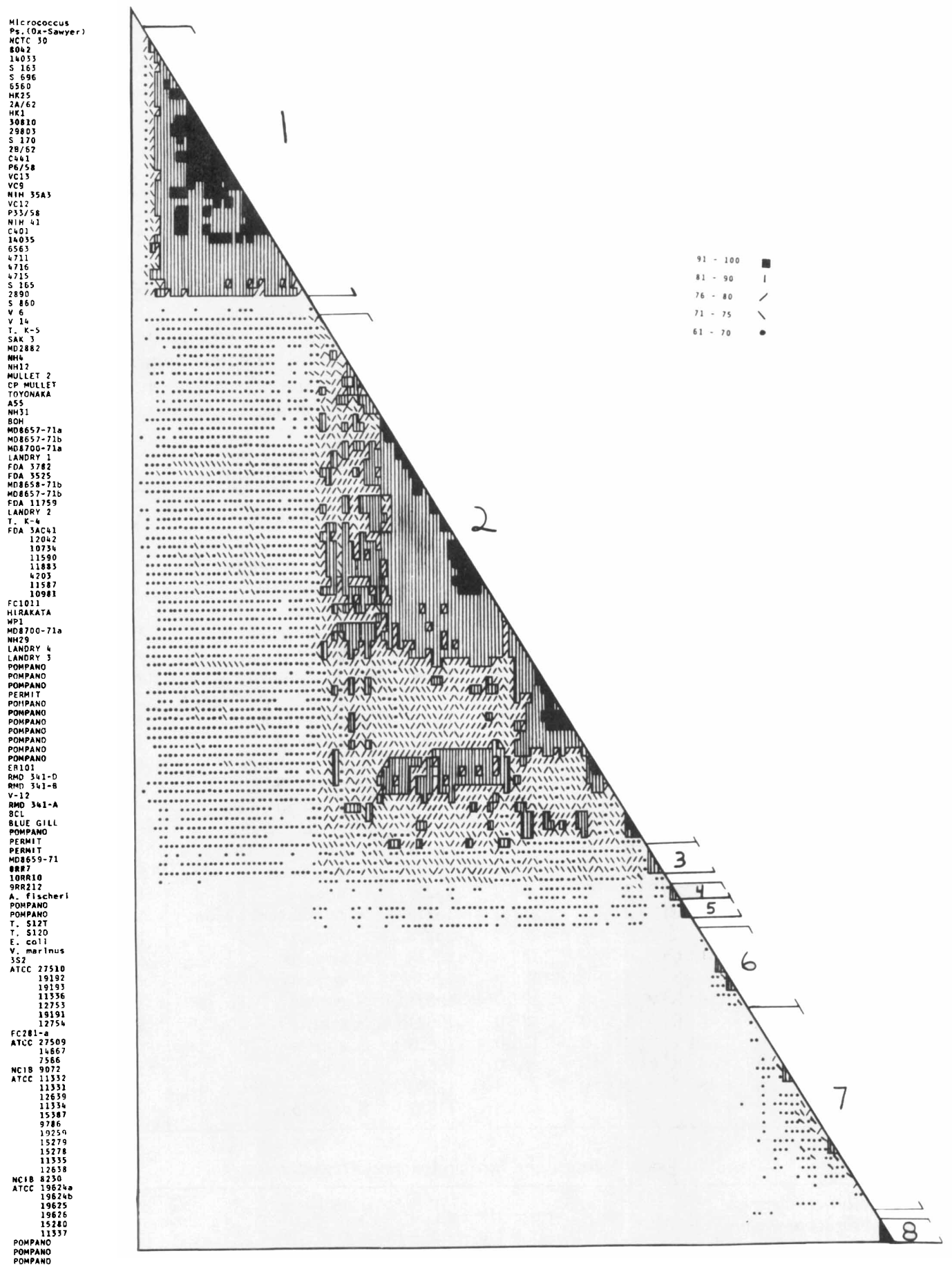

Fig. 1. Similarity matrix showing eight clusters: (1) V. cholerae, (2) V. parahaemolyticus, (3) luminescent strains, (4) Thompson cultures, (5) Pompano isolates, (6) Oceanospirillum spp., (7) Aquaspirillum spp., (8) Pompano isolates. 
ment for sodium chloride and was not found to be closely related to any of the other Spirillum strains.

Of the nine unclustered strains, five were reference strains, viz., Escherichia coli, Micrococcus sp., Pseudomonas sp., Vibrio marinus strain PS 207, and Achromobacter fischeri. The marine isolate, strain 3S2, demonstrated low similarity $(61 \%)$ to the other spirilla.

TABLE 2. Summary of differential characteristics

\begin{tabular}{|c|c|c|c|c|c|c|c|c|}
\hline \multirow{3}{*}{ Character } & \multicolumn{8}{|c|}{ Cluster } \\
\hline & \multirow{2}{*}{$\begin{array}{c}\begin{array}{c}V . \\
\text { cholerae }\end{array} \\
1\end{array}$} & \multicolumn{4}{|c|}{$\begin{array}{l}V . \text { parahae- } \\
\text { molyticus }\end{array}$} & \multirow{2}{*}{\begin{tabular}{|c|}
$\begin{array}{c}\text { Marine } \\
\text { spirilla }\end{array}$ \\
6
\end{tabular}} & \multicolumn{2}{|c|}{$\begin{array}{l}\text { Fresh- } \\
\text { water } \\
\text { spirilla }\end{array}$} \\
\hline & & 2 & 3 & 4 & 5 & & 7 & 8 \\
\hline Total no. & 29 & 56 & 3 & 2 & 2 & 7 & 21 & 3 \\
\hline $\begin{array}{l}\text { Oxidative } \\
\text { (glucose) }\end{array}$ & 29 & 56 & 3 & 2 & 2 & 0 & 0 & 3 \\
\hline $\begin{array}{l}\text { Fermentative } \\
\text { (glucose) }\end{array}$ & 29 & 56 & 3 & 2 & 2 & 0 & 0 & 3 \\
\hline Arabinose & 0 & 21 & 0 & 2 & 0 & 0 & 0 & 0 \\
\hline Cellobiose & 18 & 27 & 3 & 2 & 0 & 0 & 2 & 2 \\
\hline Dextrin & 29 & 49 & 3 & 0 & 0 & 0 & 0 & 0 \\
\hline Galactose & 29 & 56 & 3 & 0 & 2 & 0 & 0 & 0 \\
\hline Glycerol & 28 & 41 & 2 & 2 & 0 & 0 & 0 & 3 \\
\hline Maltose & 29 & 54 & 3 & 2 & 0 & 0 & 0 & 0 \\
\hline Mannitol & 29 & 56 & 1 & 2 & 2 & 0 & 0 & 0 \\
\hline Mannose & 26 & 55 & 3 & 2 & 2 & 0 & 0 & 0 \\
\hline Melibiose & 0 & 5 & 2 & 0 & 0 & 0 & 0 & 0 \\
\hline Sucrose & 28 & 3 & 0 & 0 & 2 & 0 & 0 & 0 \\
\hline Trehalose & 29 & 56 & 3 & 0 & 0 & 0 & 0 & 3 \\
\hline Xylose & 0 & 0 & 0 & 2 & 0 & 0 & 0 & 0 \\
\hline Amylose & 28 & 56 & 3 & 0 & 0 & 0 & 0 & 0 \\
\hline Gelatinase & 29 & 53 & 3 & 0 & 0 & 0 & 6 & 0 \\
\hline Lipase & 29 & 56 & 3 & 2 & 2 & 3 & 6 & 0 \\
\hline Oxidase & 29 & 56 & 3 & 2 & 2 & 6 & 21 & 0 \\
\hline Catalase & 29 & 56 & 3 & 2 & 2 & 7 & 20 & 3 \\
\hline Formate & 28 & 41 & 0 & 0 & 0 & 0 & 14 & 0 \\
\hline Acetate & 29 & 56 & 3 & 2 & 2 & 0 & 17 & 0 \\
\hline Casamino Acids & 29 & 56 & 3 & 2 & 2 & 0 & 18 & 0 \\
\hline L-Arginine & 29 & 46 & 0 & 0 & 2 & 0 & 3 & 0 \\
\hline L-Proline & 29 & 56 & 1 & 2 & 2 & 0 & 11 & 0 \\
\hline Indole & 29 & 56 & 3 & 0 & 2 & 0 & 0 & 0 \\
\hline $\mathrm{NH}_{4} \mathrm{H}_{2} \mathrm{PO}_{4}$ & 29 & 48 & 2 & 2 & 2 & 0 & 21 & 3 \\
\hline $\mathrm{NaCl}$ required & 0 & 56 & 3 & 2 & 2 & 7 & 0 & 3 \\
\hline
\end{tabular}

V6, V14, and $S$. lunatum, also unclustered strains, have already been discussed. None of the Vibrio or Spirillum strains demonstrated S values greater than $40 \%$ with the Pompano isolates which comprised cluster 8 . These three organisms were found to be gram-positive, fermentative, motile rods.

Differences among strains grouped within the genera Vibrio and Spirillum and between the marine and freshwater spirilla were corroborated by mol\% $\mathrm{G}+\mathrm{C}$ data (Table 4). For example, a $\mathrm{G}+\mathrm{C}$ of $41.6 \mathrm{~mol} \%$, obtained for the Thompson S-12-O culture, substantiates the consideration of the two organisms comprising cluster 5 as a species separate from $V$. parahaemolyticus which has a $\mathrm{mol} \% \mathrm{G}+\mathrm{C}$ of $45 \pm 1$. The mol\% $\mathrm{G}+\mathrm{C}$ determined for the

TABLE 4. DNA base composition of strains included in this study

\begin{tabular}{c|l|c|c}
\hline ATCC & \multicolumn{1}{|c|}{ Designation } & $T_{m}(\mathrm{C})$ & $\begin{array}{c}\mathrm{G}+\mathrm{C} \\
(\mathrm{mol} \%)\end{array}$ \\
\hline 19192 & Spirillum halophilum & 86.8 & 42.7 \\
19193 & S. minitulum & 97.0 & 44.1 \\
11336 & S. linum & 89.3 & 49.0 \\
12753 & S. atlanticum & 89.7 & 49.8 \\
19191 & S.japonicum & 88.2 & 46.1 \\
12754 & S. beijerinckii & 88.4 & 46.1 \\
& Spirillum sp. FC281-a & 94.9 & 62.4 \\
14667 & S.delicatum & 95.0 & 62.7 \\
7566 & S.tenue & 95.7 & 64.4 \\
11332 & S.polymorphum & 94.8 & 62.2 \\
11331 & S. itersonii & 94.5 & 61.4 \\
12639 & S. itersonii & 94.0 & 60.2 \\
11334 & S.giesbergeri & 92.6 & 56.8 \\
15387 & S.peregrinum & 94.0 & 60.2 \\
9786 & S. sinuosum & 92.9 & 57.6 \\
19259 & S.anulus & 93.0 & 57.8 \\
15279 & S. putridiconchylium & 90.6 & 52.0 \\
15278 & S. serpens & 89.9 & 50.0 \\
11335 & S. serpens & 95.3 & 63.4 \\
12638 & S. serpens & 89.8 & 50.0 \\
$19624 a$ & S.gracile & 95.7 & 64.4 \\
$19624 b$ & S.gracile & 95.9 & 64.9 \\
19625 & S.gracile & 95.4 & 63.7 \\
19626 & S.gracile & 95.6 & 64.1 \\
15280 & S. metamorphum & 89.8 & 50.0 \\
11337 & S. lunatum & 94.3 & 61.0 \\
\hline & & &
\end{tabular}

TABLE 3. Inter- and intragroup similarity values

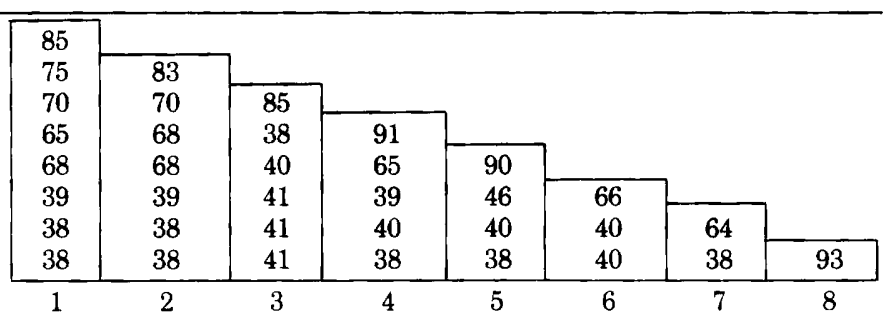


marine spirilla strains ranged from 42.7 to 49.8 . Interestingly, there was a close correspondence between the mol\% $\mathrm{G}+\mathrm{C}$ and percent $\mathrm{S}$ within this group. Spirillum halophilum and Spirillum minitulum were $86 \%$ related phenetically and demonstrated a $\mathrm{G}+\mathrm{C}$ composition of 42.7 and $44.1 \mathrm{~mol} \%$, respectively. Spirillum linum and Spirillum atlanticum $(\mathrm{S}=82 \%)$ revealed a DNA base composition of 49.0 and $49.8 \mathrm{~mol} \%$, respectively. Spirillum beijerinckii and Spirillum japonicum were found to be $72 \%$ similar, phenetically, and demonstrated a $\mathrm{G}+\mathrm{C}$ of 46.1 mol\% (Table 4). The high correlation observed between similarity values and DNA base composition was not found for all the freshwater spirilla. Within the freshwater group, the $\mathrm{G}+\mathrm{C}$ ranged from 50.0 to $64.4 \mathrm{~mol} \%$. Indeed, several of the more closely related species, namely, Spirillum serpens strains 11335 and 12638, demonstrated markedly different DNA base compositions, 63.4 and $50 \mathrm{~mol} \% \mathrm{G}+\mathrm{C}$. Data for other strains in these groups are given in Table 4.

In summary, the $V$. cholerae and $V$. parahaemolyticus strain clusters were found to be related $(S=75 \%)$ to each other but to differ significantly from both of the Spirillum groups $(\mathrm{S}=40 \%)$. Furthermore, the freshwater and marine isolates did not share high similarity values $(S=46 \%)$. Although $V$. parahemolyticus and the marine Spirillum spp. shared similar overall DNA base composition, the similarity values obtained indicated a rather low relationship between these groups. The freshwater Spirillum spp. yielded $\mathrm{G}+\mathrm{C}$ values ranging from 50 to $64.4 \mathrm{~mol} \%$, markedly different from those of the other major clusters.

\section{DISCUSSION}

Analysis of results obtained in this study of Vibrio and Spirillum spp. illustrates some of the problems encountered in bacterial taxonomy. Morphology, as a primary factor in bacterial classification, should be critically evaluated. The importance of the source of isolation in classification has not been clearly established, nor has the level of relatedness indicating membership in a given genus or species been agreed upon by taxonomists.

After several nomenclatural reassignments, $V$. parahaemolyticus, which may or may not demonstrate cell curvature, has been placed in the genus Vibrio. Originally described as a Pasteurella sp., V. parahaemolyticus was subsequently placed in Oceanomonas, Pseudomonas, or Aeromonas by various investigators. In 1966, it was suggested that the genus Vibrio should be redefined to indicate a type of motion rather than shape (10), with the net effect of reducing the weight placed on morphology. Recently, the suggestion was made that marine vibrios should be included in the genus Beneckea (3). In this study, strains of $V$. cholerae and $V$. parahaemolyticus were found to have similarity values of $75 \% \mathrm{~S}$, which can be interpreted as a marginal level of similarity for inclusion of these species in the same genus. Nevertheless, a closer relationship of $V$. parahaemolyticus with genera other than Vibrio is not precluded.

The high level of similarity shown by the luminescent bacteria with $V$. parahaemolyticus suggests that the former are representatives of a species related to $V$. parahaemolyticus. The biochemical data and $\mathrm{G}+\mathrm{C}$ of the luminescent bacteria $(47 \mathrm{~mol} \%)$ correlate with data published by Shewan for a set of bioluminescent strains (20). Hendrie et al. suggested that $V$. fischeri and strains PS207 and MP-1 of V. marinus be put into the same species (11). The mol\% $\mathrm{G}+\mathrm{C}$ values published for these organisms are in the range 40 to 43 , with PS207 $=43$ mol\% and MP-1 $=41 \mathrm{~mol} \%(6)$, whereas the DNA base composition of the luminescent bacteria in group 3 of this study was found to be in the 47.1 to $47.3 \mathrm{~mol} \% \mathrm{G}+\mathrm{C}$ range. Several differences in carbohydrate utilization were also observed among these strains. It has been proposed that strains with these characteristics be placed in a separate genus, the name of which is in dispute (Lucibacterium or Beneckea). Further work involving DNA/DNA hybridization studies of several luminescent bacteria is planned to resolve this question.

Groups 4 and 5 showed high relationship with $V$. parahaemolyticus and $V$. cholerae but did not demonstrate all of the biochemical capabilities of these species. Furthermore, group 5 strains (Thompson strains) were found to be nonmotile under the conditions tested and in at least one case (Thompson strain S-12-O, G+C $=41.6 \mathrm{~mol} \%$ ) demonstrated significantly different overall DNA base composition.

Examination of the $V$. parahaemolyticus strain data revealed two strain subclusters of high intragroup similarity. In one case, namely that of the FDA Bainbridge strains, subcultures of the same organisms may be involved since the strains, although received from different laboratories, were obtained from the same outbreak.

The isolates from Pompano fish, all of which were sucrose positive, were acetoin negative and did not grow in $10 \%$ salt, indicating that they 
may be sucrose-positive $V$. parahaemolyticus. Sakazaki noted only one sucrose-fermenting strain of $V$. parahaemolyticus among thousands of isolates from human diarrheal stools (19). However, sucrose-positive strains may be more common in marine or estuarine environments (G. Sakaguchi, R. Sakazaki, and Y. Taheda, Int. Symp. Vibrio parahaemolyticus, in press).

The low similarity values observed between strains of the genera Vibrio and Spirillum reflect not only morphological differences but also the fact that Vibrio spp. demonstrate more versatile biochemical capabilities. The $\mathrm{S}$ values, based on morphological, physiological, nutritional and biochemical tests, were low, supported by marked differences in $\mathrm{mol} \% \mathrm{G}+\mathrm{C}$ of
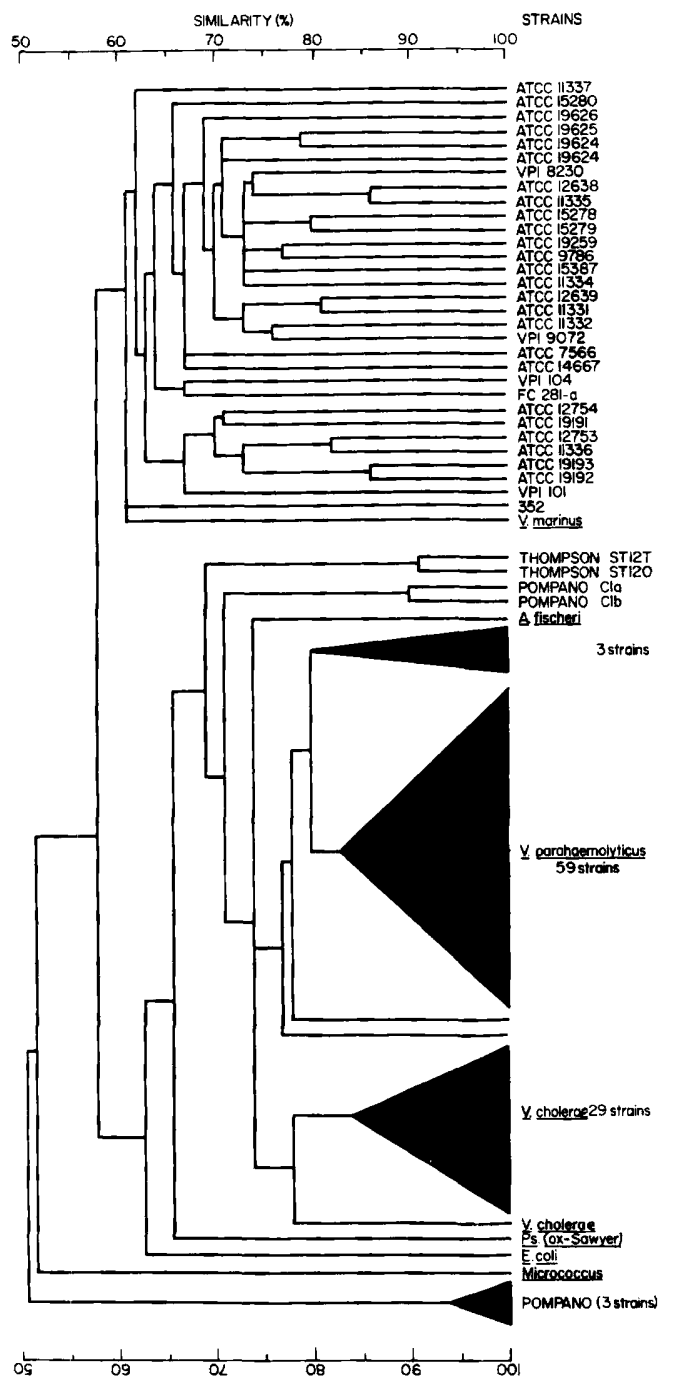

FIG. 2. Dendrogram showing the relationships among different strains. the DNA for the Vibrio and freshwater Spirillum strains. On careful examination of the phenetic data, the DNA base composition determinations for the Vibrio spp. (46 to $47 \mathrm{~mol} \%$ ) and the marine Spirillum spp. (42 to $49.8 \mathrm{~mol} \%$ ) did not provide sufficient evidence to conclude that the genera are closely related.

Although several species of Spirillum have been identified and classified on the basis of morphology, biochemical properties were not used to define species of this genus until 1936 (G. Giesberger, Ph.D. thesis, Delft University, Netherlands, 1936). All of the original Giesberger strains were lost as a result of World War II. Spirillum spp. were reisolated by Williams and Rittenberg in 1957 (26), who relied on morphology as the primary factor in classification. Despite a similarity in length or width, the variability in amplitude, wave length, and cell width makes many Spirillum species visibly distinct.

In 1972, Terasaki (23) published an extensive study of 49 Spirillum strains and included many characterisitics previously examined by others for Spirillum. More recently, Hylemon et al. (12) suggested, on the basis of a very careful study, that organisms comprising the genus Spirillum should be reclassified into three genera-Spirillum, Oceanospirillum, or Aquaspirillum.

The genetic and phenetic data of the study reported here indicate differences among the Spirillum strain clusters. However, analyses of feature frequencies (Table 2) showed that there was no set of definitive characteristics, other than salt requirement demonstrated by the marine strains, which could be used to separate the Spirillum groups phenetically. Although individual strains could be distinguished, few characters were held in common by all members of the strain clusters. The clustering of strains which was noted is substantiated by DNA base composition data, i.e., the DNA base compositions of the freshwater spirilla and the marine strains were 50 to $64 \mathrm{~mol} \% \mathrm{G}+\mathrm{C}$ and 42 to $46 \mathrm{~mol} \% \mathrm{G}+\mathrm{C}$, respectively. High $\mathrm{G}+\mathrm{C}$ content of the DNA, as well as production of a water-soluble, fluorescent pigment and presence of poly- $\beta$-hydroxybutyrate granules, observed by other investigators, suggests that some relationships between the freshwater spirilla and members of the genus Pseudomonas may exist. It would be interesting and useful to determine the degree of DNA/DNA homology between several of these organisms and selected Pseudomonas spp. The marine strains included in this study were found to be easily differentiated from Spirillum volutans, the proposed 
type species. Hylemon et al. (12) examined the characteristics of $S$. volutans and discussed those which led them to propose that the marine strains be renamed Oceanospirillum.

Several subgroupings are apparent in an examination of the dendrogram shown in Fig. 2. In most cases, the subgroupings were characterized not only by a relatively high percent of similarity but also by similar DNA base composition and antigenic properties (16). Within the cluster of marine strains, members of the subgroups demonstrated a relatively high degree of similarity, suggesting a single species, namely $S$. minitulum and $S$. halophilum, and $S$. linum and S. atlanticum. Although two other marine species, $S$. japonicum and $S$. beijerinckii, shared similar DNA base composition, they were easily differentiated on phenetic and morphological bases. VPI 101, related to the other marine strains at $67 \%$, has been named Oceanospirillum maris, ATCC 27509 (12).

Several subgroups were detected within the freshwater Spirillum cluster. In general, these were subspecies groups, such as $S$. serpens and Spirillum itersonii. One strain, received as $S$. serpens 11335, demonstrated a DNA base composition of $63.4 \mathrm{~mol} \% \mathrm{G}+\mathrm{C}$. Most probably it is a substrain of, or related to, S. serpens 11330 , the base composition of which is about $65 \mathrm{~mol} \%$ $\mathrm{G}+\mathrm{C}$. VPI 8230 and 9072 have been identified by Hylemon et al. (12) as Spirillum graniferum and Spirillum polymorphum, respectively. VPI 104 (ATCC 27510), named Aquaspirillum dispar (12), demonstrated a $67 \% \mathrm{~S}$ to the cluster of freshwater strains. Although FC281-a and 3S2 demonstrated a spiral shape under certain conditions, they were not included in the calculation of Spirillum feature frequencies (Table 2) since they are capable of fermentative utilization of glucose. S. lunatum, originally classified as a marine Spirillum, is not a salt-requiring strain and differs in several properties (i.e., DNA composition and selected carbohydrate utilization tests) from the other marine spirilla. Indeed, a lower relationship with the Spirillum cluster was observed for $S$. lunatum than for any of the other spirilla examined.

In conclusion, marked phenetic differences were observed for the genera Vibrio and Spirillum, with species of the genus Vibrio demonstrating more diverse biochemical capabilities than the Spirillum spp. The numerical taxonomy and molecular genetic data support reassignment of selected Spirillum spp. to the genera Oceanospirillum and Aquaspirillum, as proposed by Hylemon et al. (12).

\section{ACKNOWLEDGMENTS}

We thank those individuals who provided cultures used in this study, in particular Noel Krieg, who very generously supplied the Spirillum strains. The advice of Raymond Johnson and technical assistance of Jane Robinson is also acknowledged. The data have been deposited in the International Center for Data on Microorganisms, Brisbane, Australia.

This investiagtion was supported by National Science Foundation Grant No. GB-35261X.

\section{REPRINT REQUESTS}

Address reprint requests to: Dr. R. R. Colwell. Department of Microbiology, University of Maryland, College Park, Md. 20742.

\section{LITERATURE CITED}

1. Barrow, G. I., and D. C. Miller. 1972. Vibrio parahaemolyticus: a potential pathogen from marine sources in Britain. Lancet 1:485-486.

2. Battey, Y. M., R. B. Wallace, C. Allen, and B. M. Keefe. 1970. Gastroenteritis in Australia caused by a marine vibrio. Med. J. Aust. 1:430-433.

3. Baumann, P., L. Baumann, and M. Mandel. 1971. Taxonomy of marine bacteria: the genus Beneckea. J. Bacteriol. 107:268-295.

4. Baumann, L., P. Baumann, M. Mandel, and R. Allen. 1972. Taxonomy of aerobic marine eubacteria. J. Bacteriol. 110:402-429.

5. Beard, J. H., R. Nelson, A. Salinger, J. Molenda, and J. D. Stafford. 1972. Vibrio parahaemolyticus gastroenteritis-Maryland. Morbid. Mortal. Week. Rep. 21:245-246.

6. Citarella, R. V. and R. R. Colwell. 1970. Polyphasic taxonomy of the genus Vibrio: polynucleotide sequence relationships among selected Vibrio species. J. Bacteriol. 104:434-442.

7. Colwell, R. R. 1964. A study of features used in the diagnosis of Pseudomonas aeruginosa. J. Gen. Microbiol. 37:181-194.

8. Colwell, R. R. 1970. Polyphasic taxonomy of the genus Vibrio: numerical taxonomy of Vibrio cholerae, Vibrio parahaemolyticus, and related strains. J. Bacteriol. 104:410-433.

9. Dadisman, T. A., Jr., R. Nelson, J. R. Molenda, and H. J. Garber. 1973. Vibrio parahaemolyticus gastroenteritis in Maryland. I. Clinical and epidemiologic aspects. Amer. J. Epidemiol. 96:414-426.

10. Feeley, John C. 1966. Minutes of IAMS Subcommittee on taxonomy of Vibrios. Int. J. Syst. Bacteriol. $16: 135-143$.

11. Hendrie, M. S., W. Hodgkiss, and J. M. Shewan. 1971. Proposal that Vibrio marinus(Russell 1891) Ford 1927 be amalgamated with Vibrio fischeri (Beijerincki 1889) Lehmann and Neumann 1896. Int. J. Syst. Bacteriol. 21:217-221.

12. Hylemon, P. B., J. S. Wells, Jr., N. R. Krieg, and H. W. Jannasch. 1973. The genus Spirillum: a taxonomic study. Int. J. Syst. Bacteriol. 23:340-380.

13. Kaneko, T., and R. R. Colwell. 1973. Ecology of Vibrio parahaemolyticus in Chesapeake Bay. J. Bacteriol. 113:24-32.

14. Liston, J., W. Weibe, and R. R. Colwell. 1963. Quantitiative approach to the study of bacterial species. J. Bacteriol. 85:1061-1070.

15. Lovelace, T. E., and R. R. Colwell. 1968. A multi-point inoculator for petri dishes. Appl. Microbiol. 16:944-945.

16. McElroy, L. J., and N. R. Krieg. 1972. A serological method for the identification of Spirilla. Can. J. Microbiol. 18:57-65.

17. Marmur, J., and P. Doty. 1962. Determination of the base composition of deoxyribonucleic acid from its thermal denaturation temperature. J. Mol. Biol. 5:109-118. 
18. Moffett, M., and R. R. Colwell. 1968. Adansonian analysis of the Rhizobiaceae. J. Gen. Microbiol. 51:245-266.

19. Sakazaki, R., S. Iwanami, and H. Fukumi. 1963. Studies on the enteropathogenic, facultatively halophilic bacteria, Vibrio parahaemolyticus. I. Morphological, cultural and biochemical properties and its taxonomic position. Jap. Med. Sci. Biol. 16:161-188.

20. Shewan, J. M. 1971. The microbiology of fish and fishery products-a progress report. J. Appl. Bacteriol. 34:299-315.

21. Sneath, P. H. A., and R. R. Sokal. 1973. Numerical taxonomy. W. H. Freeman and Co., San Francisco.

22. Staley, T. E., and R. R. Colwell. 1973. Polynucleotide sequence relationships among Japanese and American strains of $V$. parahaemolyticus. J. Bacteriol. 114:916-927.

23. Terasaki, Y. 1972. Studies on the genus Spirillum Ehrenberg. I. Morphological, physiological, and biochemical characterisitics of water spirilla. Bull. Suzugamine Women's Coll. Nat. Sci. 16:1-146.
24. Twedt, R. M., L. Spaulding, and H. E. Hull. 1969. Morphological, cultural, biochemical and serological comparisons of Japanese strains of Vibrio parahaemolyticus with related cultures isolated in the United States. J. Bacteriol. 98:511-518.

25. Unemoto, T., T. Tsuruoka, and M. Hayashi. 1973. Role of $\mathrm{Na}^{+}$and $\mathrm{K}^{+}$in preventing lysis of a slightly halophilic Vibrio alginolyticus. Can. J. Microbiol. 19:563-571.

26. Williams, M. A. 1959 . Some problems in the identification and classification of species of Spirillum. I. Earlier taxonomy of the genus Spirillum. Int. Bull. Bacteriol. Nomencl. Taxon. 9:35-55.

27. Williams, M. A. 1959. Some problems in the identification and classification of species of Spirillum. II. Later taxonomy of the genus Spirillum. Int. Bull. Bacteriol. Nomencl. Taxon. 9:137-155.

28. Williams, M. A., and S. C. Rittenberg. 1957. A taxonomic study of the genus Spirillum Ehrenberg. Int. Bull. Bacteriol. Nomencl. 7:49-110. 